\title{
Seaweed distribution patterns as revealed by ordination with reference to the Atlantic and southern Oceans*
}

\author{
G. W. Lawson** \\ Department of Biological Sciences, Bayero University; Kano, Nigeria
}

\begin{abstract}
Ordination by Reciprocal Averaging (RA) and Detrended Correspondence Analysis (DECORANA) have been applied to problems of distribution of marine algal floras. The limitations and effectiveness of such methods are discussed and the need to analyse floras as assemblies of species per se rather than being chosen as characterising marine climates is stressed. The openended nature of RA and DECORANA is emphasised as particularly useful in phytogeography with examples from Ascension and Bioko Islands.
\end{abstract}

\section{INTRODUCTION}

Techniques of numerical classification and ordination have been used in biology mainly for the analysis of ecological problems of relatively small scale but there is no reason why they should not be applied to problems of much wider extent. I believe van den Hoek (1975) was the first to make use of such numerical methods for phytogeographical analysis of marine floras on the wider scale when he employed an agglomerative classificatory method - a type of cluster analysis - in a study of floras of the northern Atlantic.

Shortly afterwards, I attempted to analyse floras of the tropical Atlantic by a variety of numerical methods (Lawson, 1978). It seemed to me, for a number of reasons, that the use of most types of classification had certain unsatisfactory features but the most successful of these was a divisive polythetic method known as "Indicator Species Analysis", itself based on an ordination method (Hill et al., 1975). I came to the conclusion, however, that ordination by "Reciprocal Averaging" (RA) was probably the most satisfactory method to give useful results for this type of problem (Hill, 1973). In a subsequent paper read at the International Botanical Congress, Sydney (1981) and as yet unpublished, data from the southern oceans were examined by "Detrended Correspondence Analysis" (DECORANA) (Hill, 1979), a somewhat improved version of RA. I believe that van den Hoek and Joosten must also have reached this conclusion as they made use of DECORANA in a paper in which they attempted to analyse the relationships between red algal floras on a worldwide basis (Joosten \& van den Hoek, 1986). In the present paper a critical look at some of the methodology and the results so far achieved in using this type of ordination will be attempted.

\footnotetext{
- Paper presented at the XIV International Botanical Congress (Berlin, 24 July-1 August, 1987), Symposium 6-15, "Biogeography of marine benthic algae".

$\because$ Present address: 23 Sheffield Tce., London W8 7 NQ 


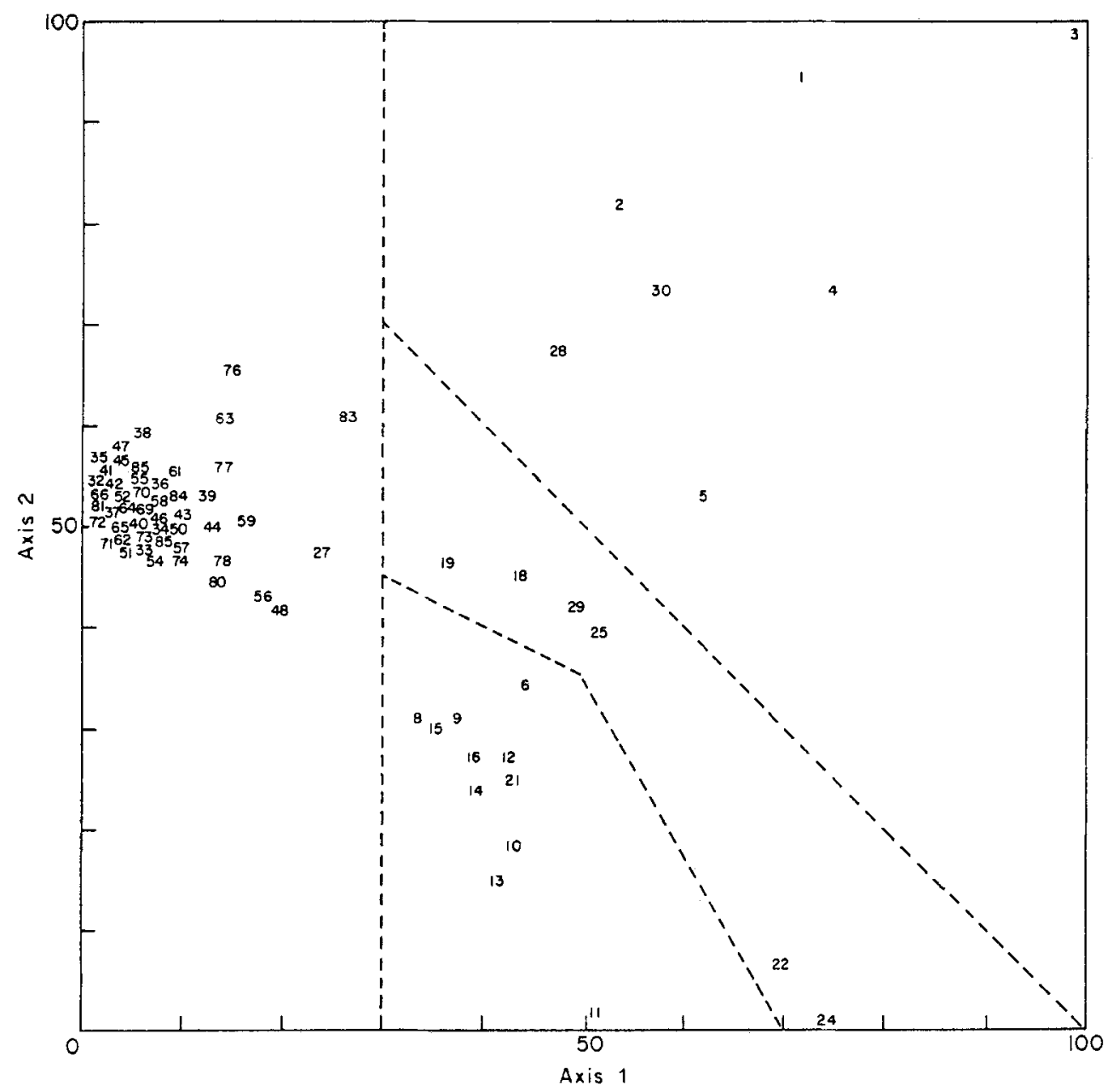

Fig. 1. Ordination of warm water seaweed floras of the Atlantic (after Lawson, 1978). 1 Salvage Is.; 2 Canary Is.; 3 Western Sahara; 4 Mauritania; 5 Sénégal; 6 Gambia; 7 Guinea Bissau; 8 Guineé; 9 Sierra Leone; 10 Liberia; 11 Ivory Coast; 12 Ghana; 13 Togo; 14 Benin; 15 Nigeria; 16 Cameroun; 17 Bioko; 18 Príncipe; 19 São Tomé; 20 Equatorial Guinea; 21 Gabon; 22 Congo Republíc; 23 Cabinda; 24 Zaire; 25 Angola; 26 Namibia; 27 Ascension I.; 28 St. Helena; 29 Annobon; 30 Cape Verde Is.; 31 Alabama; 32 Anguila; 33 Antigua; 34 Aves I.; 35 Bahamas; 36 Barbados; 37 Barbuda; 38 Bermuda; 39 Brazil $_{\text {; }} 40$ Belize; 41 Caicos I.; 42 Cayman Is.; 43 Columbia; 44 Costa Rica; 45 Cuba; 46 Dominica; 47 Florida; 48 Fr. Guiana; 49 Georgia; 50 Granada; 51 Grenadines; 52 Guadeloupe; 53 Guatemala; 54 Hispaniola; 55 Jamaica; 56 Louisiana; 57 Martinique; 58 Mexico; 59 Mississippi; 60 Montserrat; 61 Netherlands Antilles; 62 Nevis; 63 N Carolina; 64 Old Providence I.; 65 Panama; 66 Puerto Rico; 67 Redondo I., 68 Saba Bank; 69 St. Barthelemy; 70 St. Eustatius; 71 St. Kitts; 72 St. Lucia; 73 St. Martin; 74 St. Vincent; 75 Salt Key Bank; 76 S Carolina; 77 Texas; 78 Tobago; 79 Tortola I.; 80 Trinidad; 81 Trinidade $I_{\text {.; }} 82$ Turks I.; 83 Uruguay; 84 Venezuela; 85 Virgin Is.; 86 Guyana; 87 Surinam 


\section{RESULTS AND DISCUSSION}

My first paper on this topic (Lawson, 1978) had already drawn attention to some of the limitations and possible sources of error; for example, the difficulties in correct identification of species over considerable geographical areas, and the varying size of sample areas for floras when whole countries or islands of different sizes are used. With regard to the first, even when a lot of trouble is taken with accuracy there are bound to be errors in naming but as the whole flora is being considered a few errors are probably not of too much importance. Joosten and van den Hoek have avoided this problem in their study of red algae by taking only generic names which are, of course, much less likely to be incorrect than specific ones, but with increase in accuracy there is, however, inevitably some loss of information. With regard to the size of sample area it would be ideal if one were able to take the flora of, say, 250 or 500 miles of coast as a standard unit of sample size but such information is, unfortunately, hardly ever available.

One aspect which has not been touched on before is the question of the geographical area to which a particular species has most affinities. RA gives a simultaneous and directly comparable ordination of both sites and species. In my analysis of the tropical Atlantic each island of the Caribbean was given separate status as a sample site. Now as can be seen from the ordination (Fig. 1), all of these floras, as might be expected, are very closely related to one another. The species ordination indicates that many species have

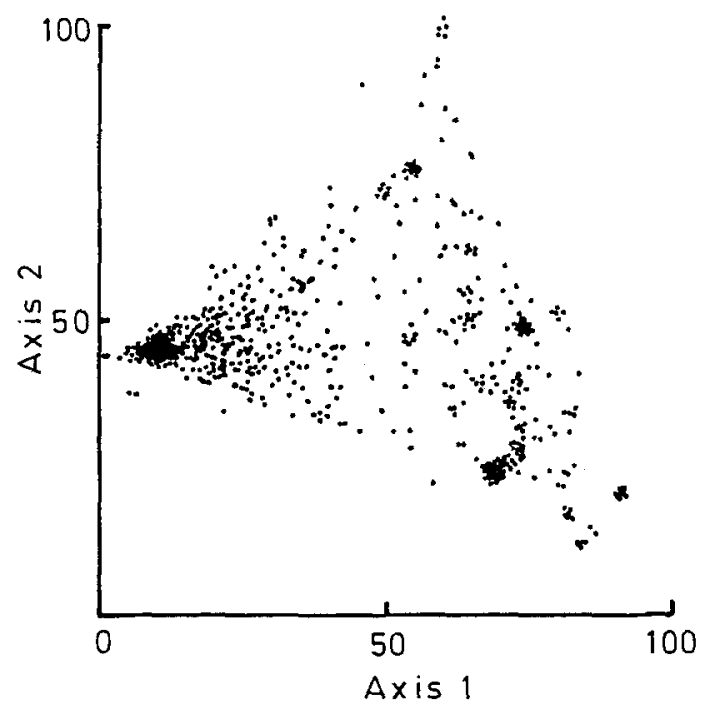

Fig. 2. Ordination by Reciprocal Averaging of seaweed species of the tropical Atlantic

their main affinities in the corresponding position (Fig. 2). If all the Caribbean islands, however, had been taken together as representing one geographical site, would the picture have been the same? This possibility has not yet been investigated but it is hoped to deal with this in a future paper. It may be that some, at least, of the points representing species associations would move to the other side of the graph indicating that their main affinities might be on the eastern side of the Atlantic. Nevertheless because of the much 
greater diversity of flora on the western side of the Atlantic than on the eastern side it is unlikely that any such changes would alter the general picture appreciably.

Another point that may be considered here concerns Joosten and van den Hoek's treatment of red algal floras of the world. Their ordination (Fig. 3) shows that the main axis, axis one, is clearly related to temperature, tropical at left through warm and cold temperate to arctic and antarctic on the right. However, is it surprising to find that this is so when the sites were initially chosen on the basis of temperature? As they say "The regions were defined by their temperature regimes. It should be stressed that the boundaries between these regions do not necessarily coincide with floristic discontinuities." Axis two which separates northern hemisphere (open symbols) and southern hemisphere (closed symbols) floras is more informative.

My firm belief is that if the aim is to try to find the relationships of floras to one another the concern should be strictly with the floras themselves and their species composition, and that this should not be confused by giving attention to possible factors causing distribution. Such factors can be super-imposed later if necessary and their importance will be revealed in due course. For example, my analysis of tropical Atlantic floras referred to earlier was initially concerned only with species composition and the map produced dealt solely with the relationships of floras to one another (Fig. 4). It should be noticed that for the African side of the Atlantic the ordination apparently separated a northern tropical group lying to the north of the equator from a southern tropical group, including three Gulf of Guinea islands, lying to the south of it. However, taking, for example, the map of mean sea temperatures from Ekman (1953), there is clearly a

\section{REGIONS}

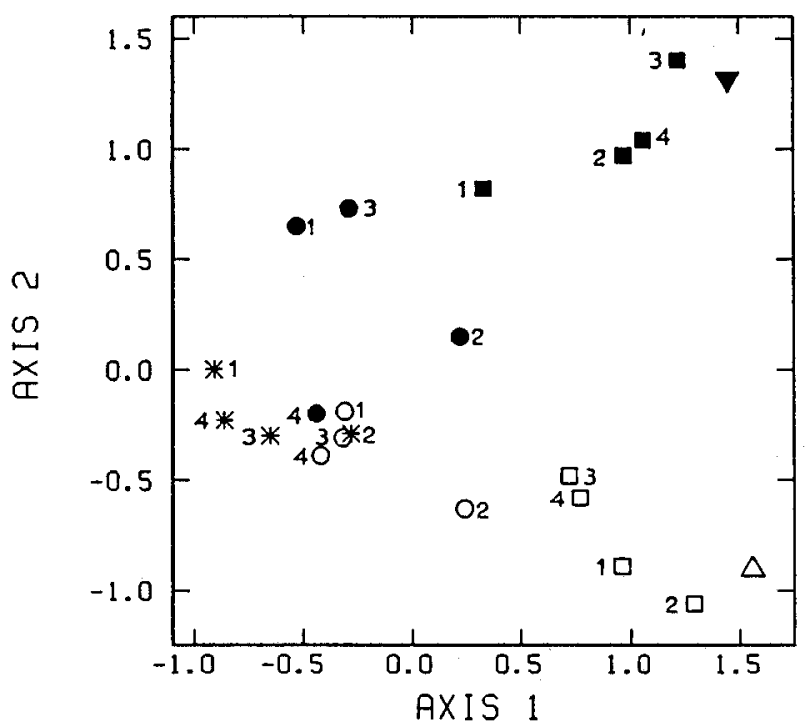

Fig. 3. Ordination of red algal floras of 22 regions of the world (after Joosten \& van den Hoek, 1986). Open symbols: regions in the northern hemisphere; closed symbols: regions in the southern hemisphere; asterisks: tropical regions; circles: warm temperate regions; squares: cold temperate regions; triangles: Arctic and Antarctic regions; $1=$ western Pacific regions; 2 = eastern Pacific regions; $3=$ eastern Atlantic regions; $4=$ western Atlantic regions 


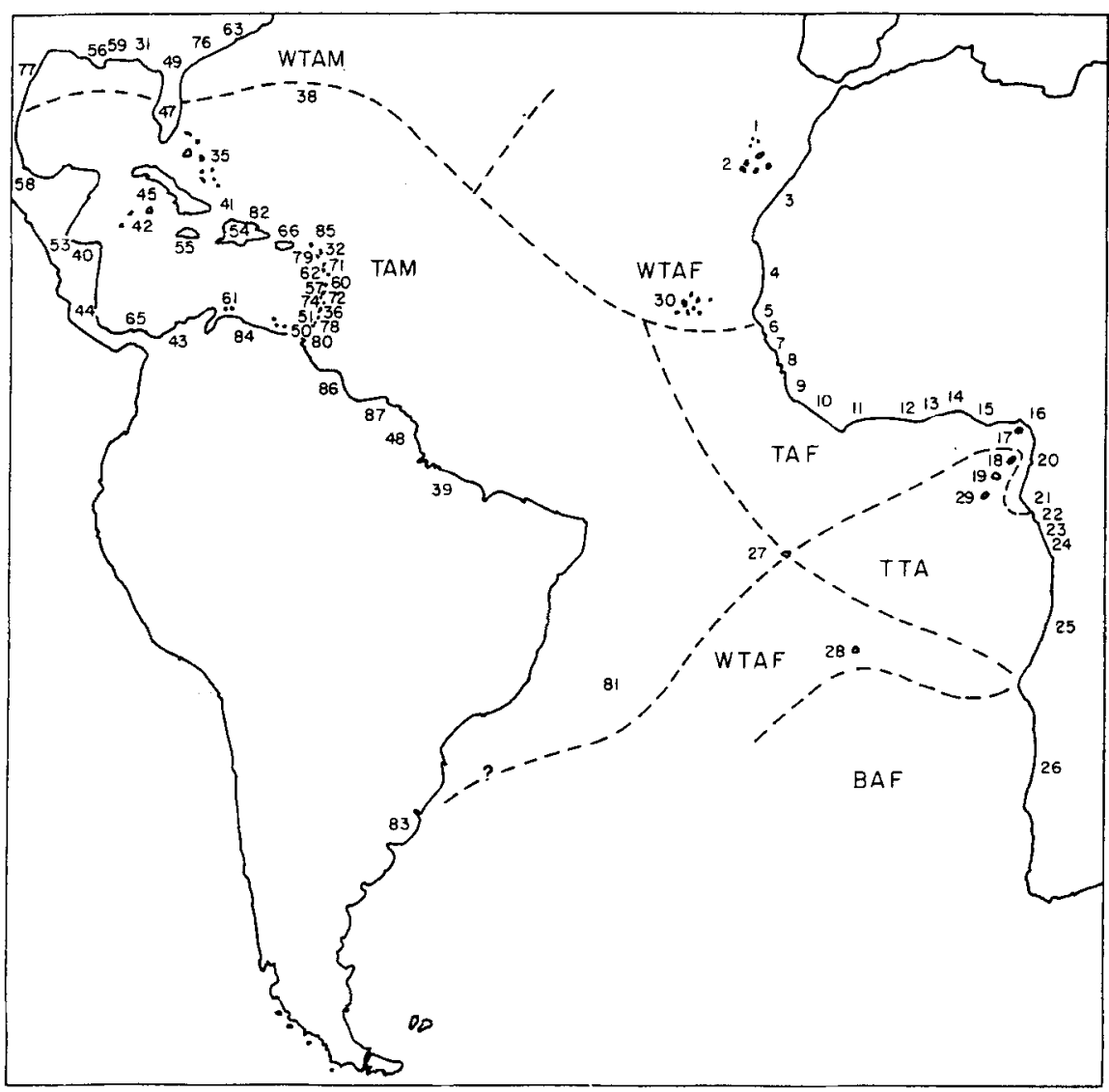

Fig. 4. Map showing groupings of warm water floras of the Atlantic based on the ordination in Figure 1. WTAM $=$ Warm Temperate American; WTAF $=$ Warm Temperate African; TAM $=$ Tropical American; TAF $=$ Tropical African; TTA $=$ Tropical Transitional African; BAF $=$ Boreal Antiboreal African (after Lawson, 1978)

considerable correspondence between distribution and temperature (Fig.5). Furthermore, this map (Fig.5) now indicates a possible reason for the separation on the ordination of a northern and southern section to the tropical flora of the eastern Atlantic since the sea temperature regimes are now seen to be different with a mean of over $25^{\circ} \mathrm{C}$ for the northern section and a mean of $20^{\circ}-25^{\circ} \mathrm{C}$ for the southern. This is not to say, of course, that it might not be possible to get an even better relationship by considering other possibilities, say extremes of temperature, than means. One point worthy of comment is that three of the Gulf of Guinea islands (Nos 18,19, and 20) fall into the southern tropical African group rather than the northern. This may be due to a somewhat lower sea temperature offshore than near the African mainland.

Again, referring to Joosten and van den Hoek's ordination, their map (Fig. 6) lumps the two areas just mentioned above as one tropical region $\left(T_{3}\right)$, but more importantly the whole of the South African Cape region is taken as one warm temperate unit. Now as is well known, for example from the work of Stephenson and his co-workers, three faunas, 


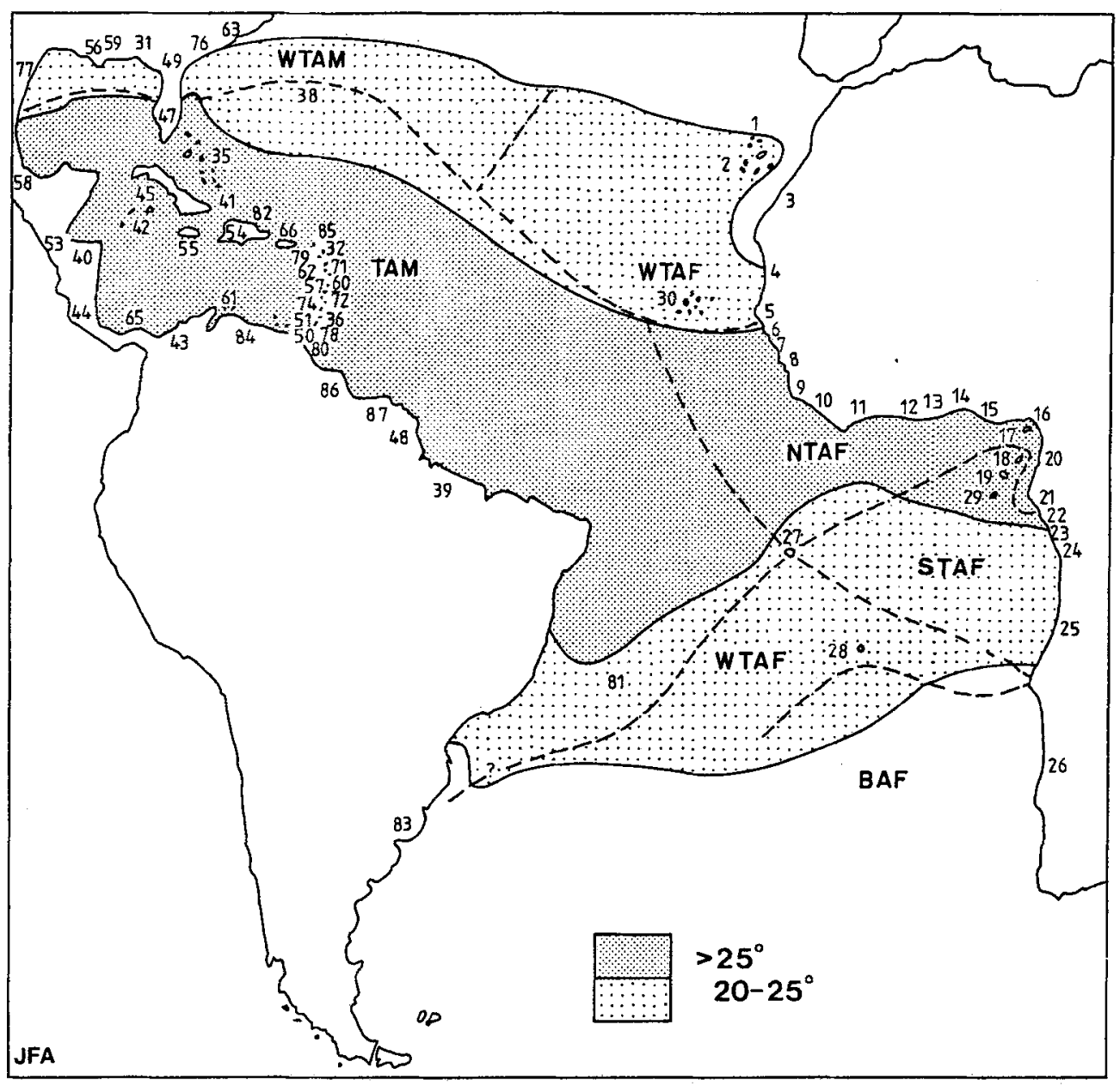

Fig.5. Superimposition of parts of map in Figure 4 and mean annual temperatures of the surface waters of the Atlantic (after Ekman, 1953) to show the relationship between the distribution of seaweed floras and surface water temperature in the warmer waters of the Atlantic. WTAM $=$ Warm Temperate American; WTAF $=$ Warm Temperate African; TAM $=$ Tropical American; NTAF $=$ North Tropical African (= TAF, Tropical African in Fig. 4); STAF = South Tropical African (= TTA, Tropical Transitional African in Fig. 4); BAF = Boreal Antiboreal African

and almost certainly three floras, are involved, one on the western side, one on the eastern side, and an intermediate one lying on the south coast of southern Africa with considerable overlaps between each. To Iump these together on the basis of sea temperature and regard them all as one warm temperate unit seems to me therefore to be taking a step backwards.

The western side of southern Africa is a somewhat controversial area having been regarded by some authorities such as Stephenson \& Stephenson (1972) and Hedgepeth (1957) as cold temperate and by others e.g. Briggs (1974), Lüning (1985), and Bolton (1986) as warm temperate. Hedgepeth's use of the term "Boreal-Antiboreal" was 


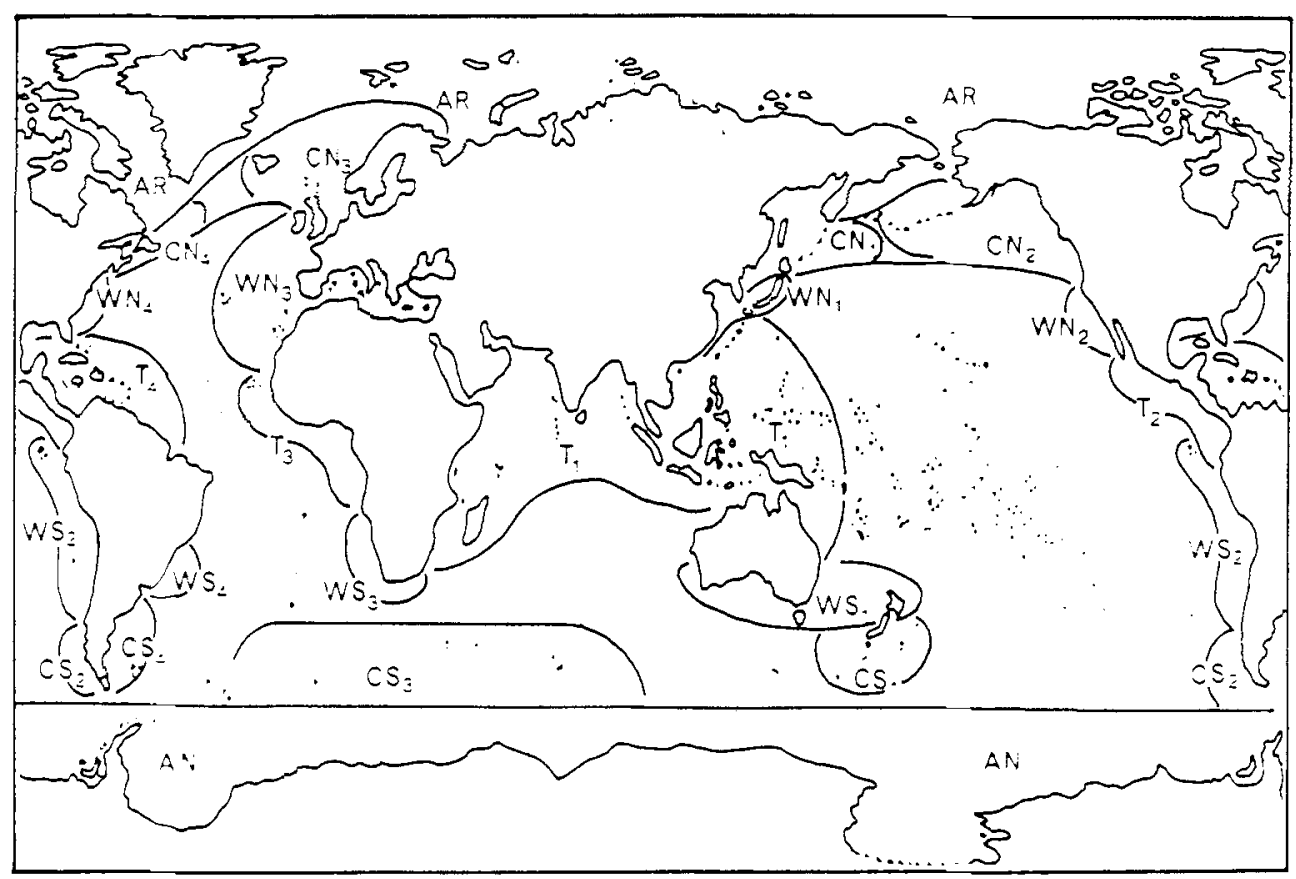

Fig. 6. The world's 22 phytogeographic seaweed regions (after Joosten \& van den Hoek, 1986). 1, AR $=$ Arctic; $2, \mathrm{CN}_{i}=$ Cold temperate NW Pacific; $3, \mathrm{CN}_{2}=$ Cold temperate NE Pacific; $4, \mathrm{CN}_{3}=$ Cold temperate NE Atiantic; $5, \mathrm{CN}_{4}=$ Cold temperate NW Atlantic $6_{1}, \mathrm{WN}_{1}=\mathrm{Warm}_{\mathrm{i}}$ temperate $\mathrm{NW}$ Pacific; 7, $\mathrm{WN}_{2}=$ Warm temperate NE Pacific; $8, W N_{3}=$ Warm temperate NE Atlantic; $9, W_{4}=$ Warm temperate NW Atlantic; $10, \mathrm{~T}_{1}=$ Tropical Indo-W Pacific; $11, \mathrm{~T}_{2}=$ Tropical E Pacific; $12, \mathrm{~T}_{3}=$ Tropical E Atlantic $; 13, T_{4}=$ Tropical W Atlantic; $14, W S_{1}=$ Warm temperate SW Pacific; $15, W_{2}=$ Warm temperate SE Pacific; $16, \mathrm{WS}_{3}=$ Warm temperate SE Atlantic; $17, \mathrm{WS}_{4}=$ Warm temperate SW Atlantic $; 18, \mathrm{CS}_{1}=$ Cold temperate SW Pacific $; 19, \mathrm{CS}_{2}=$ Cold temperate SE Pacific $; 20, \mathrm{CS}_{3}=$ Cold temperate SE Atlantic; $21, \mathrm{CS}_{4}=$ Cold temperate SW Atlantic; 22, AN = Antarctic

followed by Lawson (1978) and has therefore been adhered to in the present article (see Fig.5) though as indicated below there is some reason to regard the area as warm temperate on the basis of a comparison of the ordination of warm Atlantic floras with that of the southern oceans.

While ordination shows the relationships between floras and indicates the groups they may fall into, it tells us nothing about the status of such groups, for instance whether they are tropical or temperate, or whether they are to be regarded as provinces or subprovinces or whatever in the conventional terminology of phytogeography. An examination of the results obtained may, however, give some clues.

The tropical Atlantic ordination already mentioned (Lawson, 1978) showed that the Namibian marine flora is certainly very different from the tropical African floras but does not tell us whether the difference is from tropical to warm temperate, or from warm temperate to cold temperate, or a jump directly from tropical to cold temperate as Hedgepeth's map would indicate (Hedgepeth, 1957, Plate 1).

In the analysis of southern and antarctic floras mentioned earlier, I found (Fig. 8) that the flora of the western side of South Africa (No. 28) forms a group with those of Namibia 


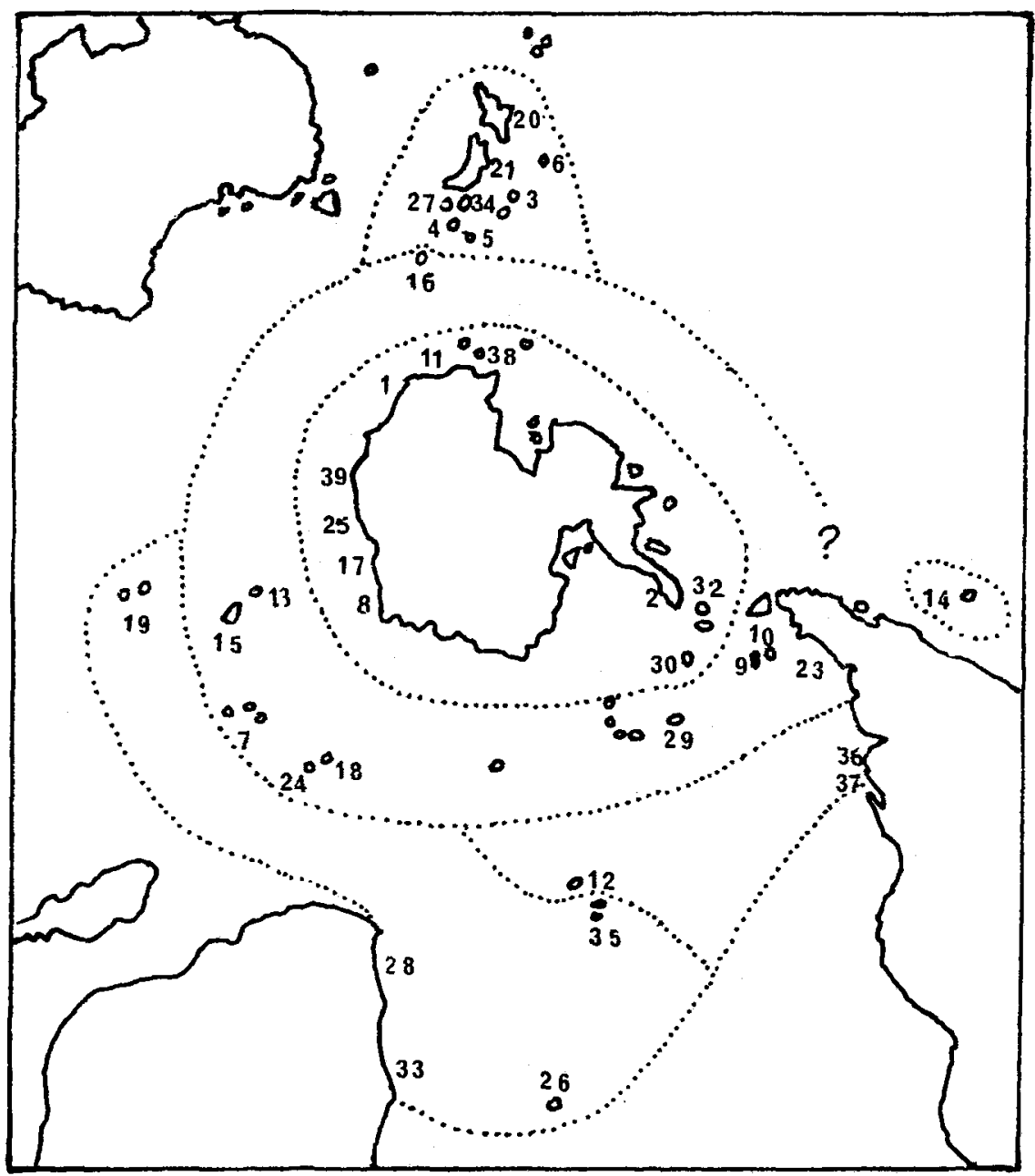

Fig. 7. Distribution of seaweed floras in the southern oceans [after Lawson (unpubl.), from a paper entitled "Marine algal floras of the southern oceans: a numerical analysis" read at the XII International Botanical Congress, Sydney, Australia, August, 1981]. 1 Adelie Coast; 2 Antarctic Peninsula; 3 Antipodes Is.; 4 Auckland I.; 5 Campbell I.; 6 Chatham I.; 7 Crozet; 8 Enderby Land; 9 Falkland Is.; 10 Fuegia; 11 George V Coast; 12 Gough I.; 13 Heard I.; 14 Juan Fernandes I.; 15 Kerguelen; 16 Macquarie I.; 17 MacRobertson Coast; 18 Marion I.; 19 New Amsterdam and St. Paul Is.; 20 New Zealand (North I.); 21 New Zealand (South I.); 23 Patagonia; 24 Prince Edward I.; 25 Queen Mary Coast; 26 St. Helena; 27 Snares I.; 28 South Africa; 29 South Georgia; 30 South Orkneys; 32 South Shetland Is.; 33 Namibia; 34 Stewart I.; 35 Tristan da Cunha; 36 UruguayoBonaerense; 37 Uruguay; 38 Victoria Land; 39 Wilke's Land

(No. 33), and some Atlantic islands such as St. Helena (No. 26), Tristan da Cunha (No. 35), as well as New Amsterdam and St. Paul's islands in the Indian Ocean (No. 19). This group was also very close to, if not identical with, a group including Uruguay (No. 37), the northern part of Argentina (No.36), and Gough Island (No.12). As the southern tip of South America is not included and if this area is regarded as truly cold temperate this 
would seem to lend support to the concept of western South Africa as warm temperate rather than cold temperate. Further support is given to this view in the fact that St. Helena is clearly in the warm temperate group in the analysis of warm water floras of the Atlantic (Fig. 1) but also close to Namibia and the western coast of South Africa as shown in the analysis of the floras of the southern oceans indicated in Figure 7. But perhaps the concern should not be too much with forcing floras into man-defined climatic categories. Floras as they exist represent an expression of the totality of all factors operating - not just physical factors but also others such as historical ones, and in this respect the problem is somewhat analogous to that of the zones of algae on rocky shores for which attempts to give a complete explanation in terms of a single factor, such as tides, have usually proved insufficient.

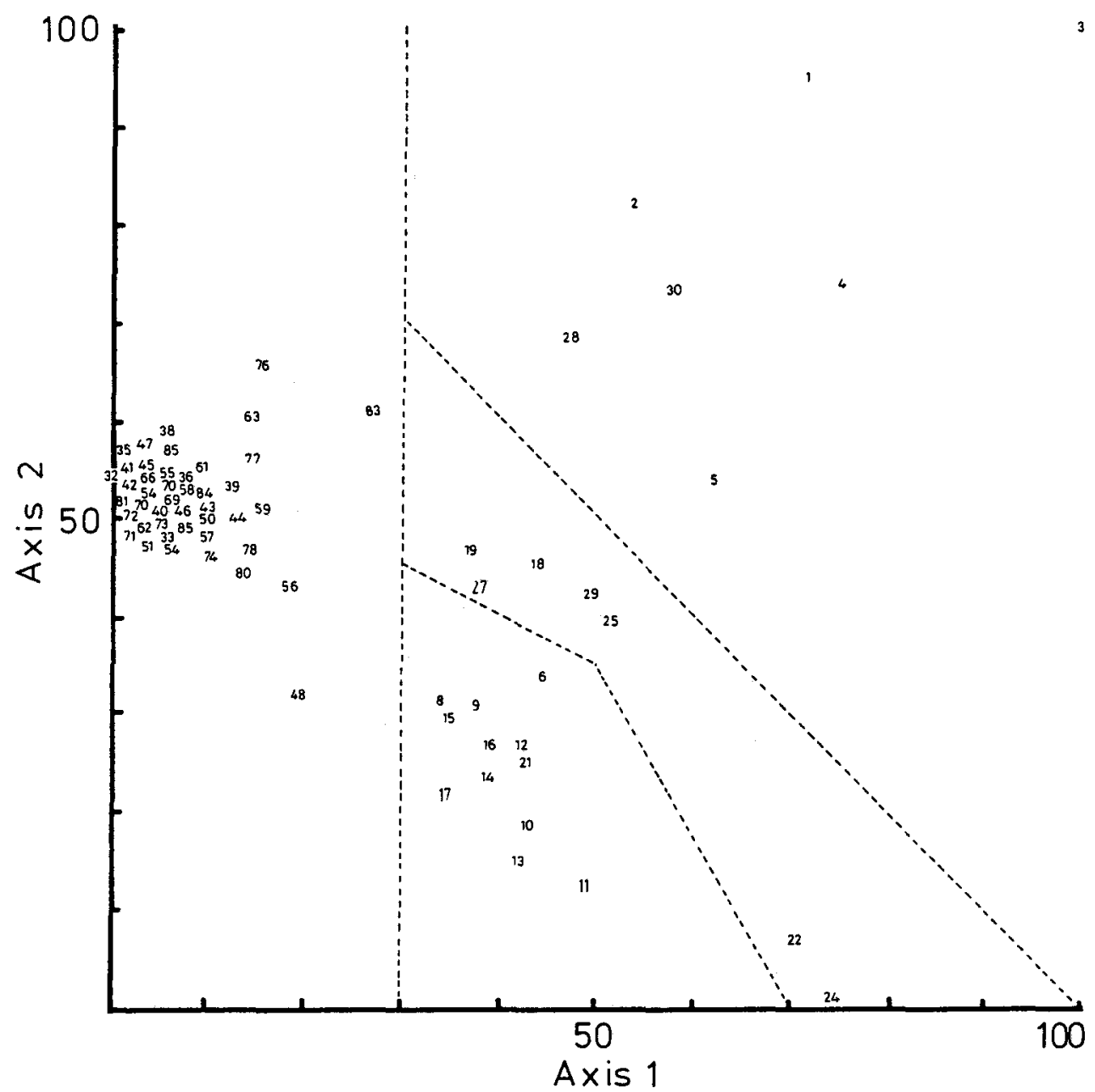

Fig. 8. Ordination of warm water seaweed floras of the Atlantic as given in Figure 1 but recalculated with new data for Ascension Island (No.27) and the insertion of Bioko (No. 17). This recalculation also causes some movement of certain other sites e.g. 11 and 48 
Some of the limitations of using ordination methods have been indicated but there are also some decided advantages. One of the most important of these as far as RA or DECORANA are concerned is that they are open-ended. Since every species has a position on each axis of the species ordination and as the site ordination is the average of these figures for all the species that occur at that site it is a simple matter to obtain an ordination of a particular site if a sufficient sample of the species present at it is available. So as new distribution data become available they can be fitted in to show the positions of new sites in the ordination. Thus, in the ordination of tropical Atlantic floras (Lawson, 1978) a very limited number of records from Ascension Island were known but these appeared to show that its flora had more affinity with those of the western Atlantic than those of the east (see Fig. 1 where Ascension Island is represented by number 27). However, after a subsequent survey of Ascension Island by Price \& John (1977), the much greater number of species found indicated, after recalculation, that Ascension Island's flora had probably more affinity with that of the Gulf of Guinea than that of the Caribbean. This is shown by the new position of Ascension Island (No.27) in Figure 8.

Similarly, when the original ordination was made there were virtually no records for Bioko (Fernando Po) except for a single species, Hydroclathrus clathratus, mentioned by Schmidt \& Gerloff (1957). After a visit to Bioko and from the thirty or so species collected it was possible to show (Lawson, unpubl.) that the site ordination put Bioko very firmly in the mainland Guinea group rather than with the other islands of the Gulf of Guinea (São Tomé, Príncipe and Annobon). Bioko is represented by number 17 in Figure 8. Thus, my original guess of separating Bioko from the other Gulf of Guinea islands on the map shown in Figure 4 was confirmed. It is also interesting to note that these other Gulf of Guinea islands have never been connected to the mainland whereas Bioko is believed to have been attached to the African continent until, relatively recently, geologically speaking.

Another advantage of ordination is that every species is taken into account, so an infrequent microscopic filament may be considered as characteristic of a flora as a common laminarian. Thus those things that might weigh heavily with the human mind such as size are looked at more objectively by the computer. A lot depends on the operator for there are many choices open to him such as weighting of species, or deciding which sites and which axes of the ordination to make use of. Thus, a certain amount of manipulation of the results is always possible.

In conclusion all that needs to be said is that there are now some very powerful tools available for the analysis of biogeographical problems - but they must be used intelligently and with care.

\section{LITERATURE CITED}

Bolton, J. J., 1986. Marine phytogeography of the Benguela upwelling region on the west coast of southern Africa: a temperature-dependent approach. - Botanica mar., 29, 251-256.

Briggs, C. J., 1974. Marine zoogeography. McGraw-Hill, New York, 475 pp.

Ekman, S., 1953. Zoogeography of the sea. Sidgwick \& Jackson, London, 417 pp.

Hedgpeth, J. W., 1957. Marine biogeography. In: Treatise on marine ecology and paleoecology. Ed. by J. W. Hedgpeth. The Geol. Soc. of America, New York, 1, 1-1296.

Hill, M. O., 1973. Reciprocal averaging: an eigenvector method of ordination. - J. Ecol. 61, $237-249$. Hill, M. O., 1979. DECORANA - A FORTRAN program for detrended correspondence analysis and reciprocal averaging. Cornell Univ., Ithaca, N.Y., $30 \mathrm{pp}$. 
Hill, M. O., Bunce, R. G. H. \& Shaw, M. W., 1975. Indicator species analysis, a divisive polythetic method of classification, and its application to a survey of native pinewoods in Scotland. -J. Ecol. $63,597-613$.

Hoek, C. van den, 1975. Phytogeographic provinces along the coasts of the northern Atlantic Ocean. - Phycologia 14, 317-330.

Joosten, A. M. T. \& Hoek, C. van den, 1986. World-wide relationships between red seaweed floras: a multivariate approach. - Botanica mar. 29, 195-214.

Lawson, G. W., 1978. The distribution of seaweed floras in the tropical and subtropical Atlantic Ocean: a quantitative approach. - Bot. J. Linn. Soc. 76, 177-193.

Lüning, K., 1985. Meeresbotanik. Thieme, Stuttgart, $375 \mathrm{pp}$.

Price, J. H. \& John, D. M., 1977. The marine flora of Ascension Island, south Atlantic. - J. Phycol. 13, 55.

Schmidt, O. C. \& Gerloff, J., 1957. Die marine Vegetation Afrikas in ihren Grundzügen dargestellt. Willdenovia 1, 709-756.

Stephenson, T. A. \& Stephenson, A., 1972. Life between tidemarks on rocky shores. Freeman, San Francisco, $425 \mathrm{pp}$. 